24 Turner RS. Autołogous blood transfusion for surgical auto transfusions. $f$ Bone foint Surg 1968;50A:834.

25 Davis R. Banked autologous blood for elective surgery. Anaesth Intensive Care 1979;7:42-4. 26 Swanson D, Lo RK, Lichtiger B. Pre-deposit autologous blood transfusion in patients undergoing radical cystectomy. F Urol 1983;130:892-4.

27 sands GJ, Wood RP, Van Schoorhoven PV. Autologous blood transfusion in head and neck surgery. Arch Otolarynogol 1968;88:423-5.

28 Milles G, Browne WH, Barrick RG. Autologous transfusion for elective Cesarean section. Am $\mathcal{J}$ Obstet Gynecol 1969;103:1166-7.

29. Peters Von M, Hölke D. Autologe Transfusion an einer orthopädischen Klinik. Anesteziol Reanimatol 1985;10:323-8.

30 Blaise G, Jackmuth R. Pre-operative autotransfusion for total hip prostheses. Acta Anoesthesiol Belg 1979;3:175-82.

31 Kruskall MS, Glazer EE, Leonard SS, et al. Utilisation and effectiveness of a hospital autologous pre-operative blood donor program. Transfusion 1986;26:335-40.

32 Kay LA, Huehns ER. Clinical blood transfusion. London: Pitman Medical, 1985:229-30.

33 Newman MM, Hamstra R, Block M. Use of banked autologous blood in elective surgery. JAMA 1971;218:861-3.

34 Allain JP, Laurian Y, Paul DA, Senn D. Serological markers in early stages of human immunodeficiency virus in haemophiliacs. Lancet 1986;i:1233-6.

\section{The flow cytometer}

The flow cytometer is one of the most exciting of recent innovations in pathology. ${ }^{2}$ It produces measurements on thousands of cells that are forced one by one at high speed through a focused light beam (usually produced by a laser). Some of the information that would be available from a microscope can be gathered in this way, but, in addition, the cytometer assigns accurate quantitative values to the information, computes the inter-relationships between the measurements, and may then sort out from the original samples cells with particular characteristics. One possibility is thus that cervical screening might be automated, but the technology is not yet good enough.

The cytometer measures simultaneously the forward and lateral light scatter (proportional to cell size and cytoplasmic optical "texture" respectively) and the intensity of any fluorescence deriving from DNA or protein seeking fluorescent tracers to which the cells have been exposed. Such tracers include DNA binding dyes (for nuclear DNA content) and a potentially limitless range of antibodies to cellular constituents, tagged with fluorochromes. Suitable fluorochromes are fluorescein and phycoerythrin, which emit at different wavelengths and so allow simultaneous double labelling.

Flow cytometers require the cells to be in an evenly dispersed suspension. Blood cells come this way naturally, and cytology specimens and lymphoid tissues can be rendered suitable by gentle physical means. Solid tissues must be digested enzymically. Thus the flow cytometer does not give any of the information on cell to cell orientation which is so important in histopathology.

Early research appliations of flow cytometry were in immunology, and modest instruments can provide good immunophenotypes from peripheral blood leucocytes. In the study of tumours applications include estimating the proportion of cells engaged in DNA synthesis and the proportion sensitive to radiation-both useful indices in monitoring treatment. Most useful, however, is the ability to measure the basal DNA content of tumour cells. The degree of DNA aneuploidy is related to the prognosis of tumours at many sites, including ovary and bladder-where histological examination is sometimes an uncertain guide to the aggressiveness of the tumour. DNA content can be measured in nuclei recovered from thick sections of specimens processed in paraffin, ${ }^{3}$ which means that the power of this new technology can be evaluated using stored blocks of tissues from patients whose ultimate clinical progress is already known. We will soon be reading many reports of studies on archival material.

The flow cytometer cannot be used for cervical screening, partly because of inadequate sensitivity. Whereas a good cytologist will be alerted by two or three abnormal cells in a smear of around 15000 cells, the cytometer would barely detect 10 times that proportion. ${ }^{4}$ Another problem is what to measure: DNA aneuploidy, although correlating with the grade of cervical intraepithelial neoplasia, ${ }^{5}$ is not a satisfactory criterion on its own. Better discrimination may be provided by simultaneous analysis of other values, and there are reasons for optimism as more antibodies to tumour markers become available, including some to oncogene proteins that are presumably close to the origins of the neoplastic process itself. An instrument operable by a skilled technician and able to discriminate between normal and atypical smears without error or fatigue would bring solace today not only to the women waiting for smear results but also to doctors, cytologists, and health board administrators -even if it costs (as good ones do) over $£ 150000$.

ANDREW H WYLLIE

Reader in Pathology,

University of Edinburgh,

Edinburgh EH8 9AG

1 Friedlander ML, Hedley DW, Taylor IW. Clinical and biological significance of aneuploidy in human tumours. $\mathcal{F}$ Clin Path 1984;37:961-74.

2 Quirke P, Dyson JED. Flow cytometry: methodology and applications in pathology. $\mathcal{J}$ Pathol 1986;149:79-87.

3 Hedley DW, Friedlander ML, Taylor IW, Rugg CA, Musgrove EA. Method for analysis of cellular DNA content of paraffin-embedded pathological material using flow cytometry. $\mathcal{F}$ Histochem Cytochem 1983;31:1333-5.

4 Valet G, Ormerod MG, Warnacke HH, Benker G, Ruhenstroth-Bauer G. Sensitive three parameter flow cytometric detection of abnormal cells in human cervical cancers: a pilot study. $\mathcal{f}$ Cancer $R$ es Clin Oncol 1981;102:177-84.

5 Jakobsen A, Back Kristensen P, Krist Poulson H. Flow cytometric classification of biopsy specimens from cervical intra-epithelial neoplasia. Cytometry 1983;4:166-9.

\section{The economics of mental health services}

The most cost effective way to deliver mental health care is not clear. ${ }^{14}$ In the move from hospital to community care the patterns of use and financing of mental health services are changing rapidly - as are the distribution and responsibilities of staff. And developing optimal services is difficult because of the lack of reliable measures of process and outcome and of the costs and benefits of identification and treatment.

In fact, different types of hospital care result in similar clinical and social outcomes. In one study newly admitted patients were randomly assigned to standard inpatient care followed by outpatient care, brief admission followed by discharge to outpatient care, or brief admission followed by day care and then discharge to outpatient care. ${ }^{5}$ Brief admission followed by either day or outpatient care was less expensive after two years than standard admission both in hospital costs and in costs to the patients' families. In a similar study patients admitted as emergencies with neurosis, personality disorder, or adjustment reaction were randomly allocated to day hospital or inpatient care. ${ }^{6}$ After one year the median length of stay for day care was twice as 